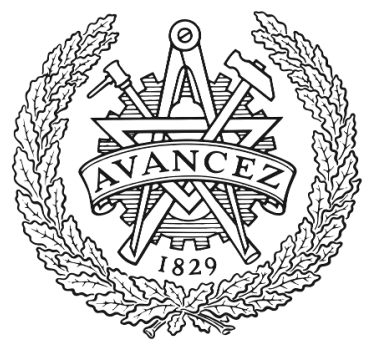

CHALMERS

UNIVERSITY OF TECHNOLOGY

\title{
Control Optimization of the Transient Performance of the Selective Bleed Variable Cycle Engine During Mode Transition
}

Downloaded from: https://research.chalmers.se, 2023-04-26 10:49 UTC

Citation for the original published paper (version of record):

Grönstedt, T., Pilidis, P. (2002). Control Optimization of the Transient Performance of the Selective Bleed Variable Cycle Engine

During Mode Transition. Journal of Engineering for Gas Turbines and Power, 124(75): 75-81

N.B. When citing this work, cite the original published paper. 


\author{
U. T. J. Grönstedt \\ Department of Thermo and Fluid Dynamics, \\ Chalmers University of Technology, \\ SE-412 96 Gothenburg, Sweden \\ e-mail: thgr@tfd.chalmers.se \\ P. Pilidis \\ School of Mechanical Engineering, \\ Cranfield University, \\ Cranfield, Bedford MK43 OAL, UK \\ e-mail: p.pilidis@cranfield.ac.uk
}

\section{Control Optimization of the Transient Performance of the Selective Bleed Variable Cycle Engine During Mode Transition}

The transient performance of the selective bleed variable cycle engine (VCE) has been optimized during the transition from subsonic to supersonic mode. The selective bleed VCE concept has been developed with a short take-off vertical landing (STOVL) aircraft in mind and the engine is characterized by its twin mode VCE feature. The transition optimization is constrained by the requirement of maintaining thrust and compressor surge margins. The engine variable geometry component schedules and the fuel flow are used as optimization variables. A differential algebraic formulation of an inter-component volume model is used to model the transient behavior of the engine. Sequential quadratic programming $(S Q P)$ is applied to the nonlinear transient engine model directly, in order to solve the multivariable control problem. It is predicted that the mode switch can be carried out safely without violating the constraints and that the time required is limited by the actuator time of the hydraulic system. [DOI: 10.1115/1.1394965]

\section{Introduction}

Selecting optimal cycle parameters for a mixed aircraft mission with substantial amounts of fuel consumption required during both supersonic and subsonic flight, normally implies great compromises in engine performance. When integrated in short take-off vertical landing (STOVL) aircraft, the selective bleed variable cycle engine shows great potential for achieving superior mixed mission performance, in comparison with conventional turbofan engines ([1]). The design target is to obtain a powerplant that enables the aircraft to take off from a very short runway, cruise economically at Mach 1.6 (dry operation), loiter at Mach 0.6, and land vertically.

The selective bleed VCE operates in two different modes depending on flight conditions; the subsonic and the supersonic mode. During subsonic operation air is bled at the back of the low pressure compressor powering a continuously vectorable convergent nozzle. The nozzle is vertically positioned for take-off and horizontally positioned for subsonic cruise. The intermediate compressor operates with closed stator vanes. During supersonic operation the front nozzle is closed and the air is discharged through a convergent-divergent nozzle. The intermediate compressor is high flowed by opening its stator vanes. This gives the rear nozzle the specific thrust suitable for dry supersonic cruise at Mach 1.6.

A number of studies assessing the performance of the selective bleed engine have been carried out at Cranfield University ([1-4]). These studies have focused on selecting a suitable engine design point for the specified aircraft mission and optimizing the steady-state control system of the engine. This work addresses the key issue of the safe and efficient handling of the transient engine performance during the switch from subsonic to supersonic mode.

All numerical tests have been conducted with a new general transient and steady-state code, GESTPAN (general stationary and transient propulsion analysis), developed at Chalmers University of Technology, The Royal Institute of Technology and at Volvo Aero Corporation ([5]). The tool has been developed using For-

Contributed by the International Gas Turbine Institute (IGTI) of THE AMERICAN SOCIETY OF MECHANICAL ENGINEERS for publication in the ASME JOURNAL OF ENGINEERING FOR GAS TURBINES AND POWER. Paper presented at the International Gas Turbine and Aeroengine Congress and Exhibition, Munich, Germany, May 8-11, 2000; Paper 00-GT-148. Manuscript received by IGTI Nov. 1999; final revision received by ASME Headquarters Feb. 2000. Associate Editor: D. R. Ballal. tran 90. For this work a dynamic connection feature was programmed, to make the use of one engine model representing all three simulation modes possible (the third mode, operation with both nozzles partially opened, is used during the mode transition transient).

\section{The Selective Bleed Engine}

The two operating modes of the selective bleed variable cycle engine are illustrated in Fig. 1.

Selection of Design Point. A detailed study on the design point optimization and cycle selection of the selective bleed VCE has been performed by Nascimento and Pilidis [1]. In that study, two separate engine models representing the subsonic and the supersonic modes were used, in combination with a matching procedure that ensured that the two cycles corresponded to the same engine design.

Since the transient operation of the mode switch must use both nozzles actively the separate engine approach was not suitable for this work. Instead the engine design was carried out in the inter-
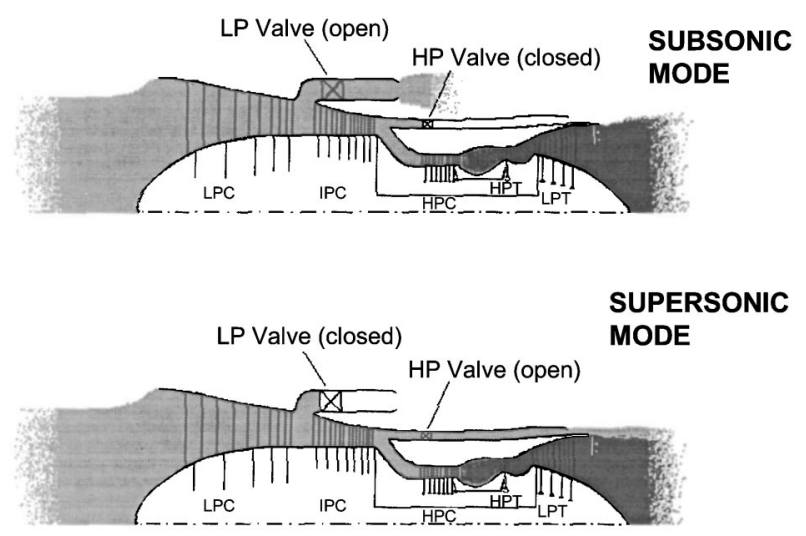

Fig. 1 The operating modes of the selective bleed engine ([4]) 
Table 1 Engine design point at SLS (sea level static)

\begin{tabular}{cccc}
\hline \hline Design Parameter & Value & Design Parameter & Value \\
\hline$h$ & $0.0 \mathrm{~m}$ & $\pi_{\mathrm{HPC}}$ & 3.60 \\
$M$ & 0.0 & $\ddot{\eta}_{\mathrm{HPC}}$ & 0.88 \\
$\pi_{\mathrm{LPC}}$ & 3.0 & $\dot{m}_{\text {core }}$ & $170 \mathrm{~kg} / \mathrm{s}$ \\
$\eta_{\mathrm{LPC}}$ & 0.88 & $\mathrm{TIT}$ & $1500.0 \mathrm{~K}$ \\
$\mathrm{BPR}_{1}$ & 0.62 & $\eta_{\mathrm{HPT}}$ & 0.90 \\
$\pi_{\mathrm{IPC}}$ & 2.40 & $\eta_{\mathrm{LPT}}$ & 0.90 \\
$\eta_{\mathrm{IPC}}$ & 0.88 & $\pi_{\text {nozzles }}$ & 0.98 \\
$\mathrm{BPR}_{2}$ & 0.24 & & \\
\hline \hline
\end{tabular}

mediate mode and a feature for dynamic connections to switch between the intermediate mode and two single nozzle modes was developed. The design point, see Table 1, was selected in such a way that it would match the mission optimized design obtained by Nascimento and Pilidis [1] as closely as possible.

Engine Variable Geometry and Controls. The engine model has six variable geometry control signals; variable geometry in all three compressors as well as in the three nozzles. Additionally, the fuel flow has to be controlled in a suitable manner, giving a total of seven degrees-of-freedom for the control optimization. The variable geometry compressor model is identically the same as the one used by Oggero and Pilidis [4] to optimize the steady-state control of the selective bleed VCE.

\section{Selection of the Transition Point}

The selection of the transition point could be made in a straight forward way. The specific fuel consumption (SFC) of the engine was minimized for a number of flight cases in both the subsonic and the supersonic mode. Subsequently, a suitable point for transition could be selected among these optimal cruise points, defining both the initial and the end point of the trajectory as well as the flight case at which the transition will occur.

To ensure safe and stable operation in the optimal cruise points a number of constraints had to be imposed on the control optimization. The constraints are given in Table 2. The same definition of surge margin as the one used for optimizing the steady-state controls of the selective bleed VCE ([4]), was used here:
Table 2 Constraints

\begin{tabular}{ccc}
\hline \hline$\Psi_{\text {LPC }}$ & $\leqslant$ & 0.8 \\
$\Psi_{\text {IPC }}$ & $\leqslant$ & 0.8 \\
$\Psi_{\text {HPC }}$ & $\leqslant$ & 0.8 \\
TIT & $\leqslant 50.0 \mathrm{~K}$ \\
Net thrust & $\geqslant$ & $134.0 \mathrm{kN}$ \\
Mass flow & $\leqslant$ & Design mass flow \\
\hline \hline
\end{tabular}

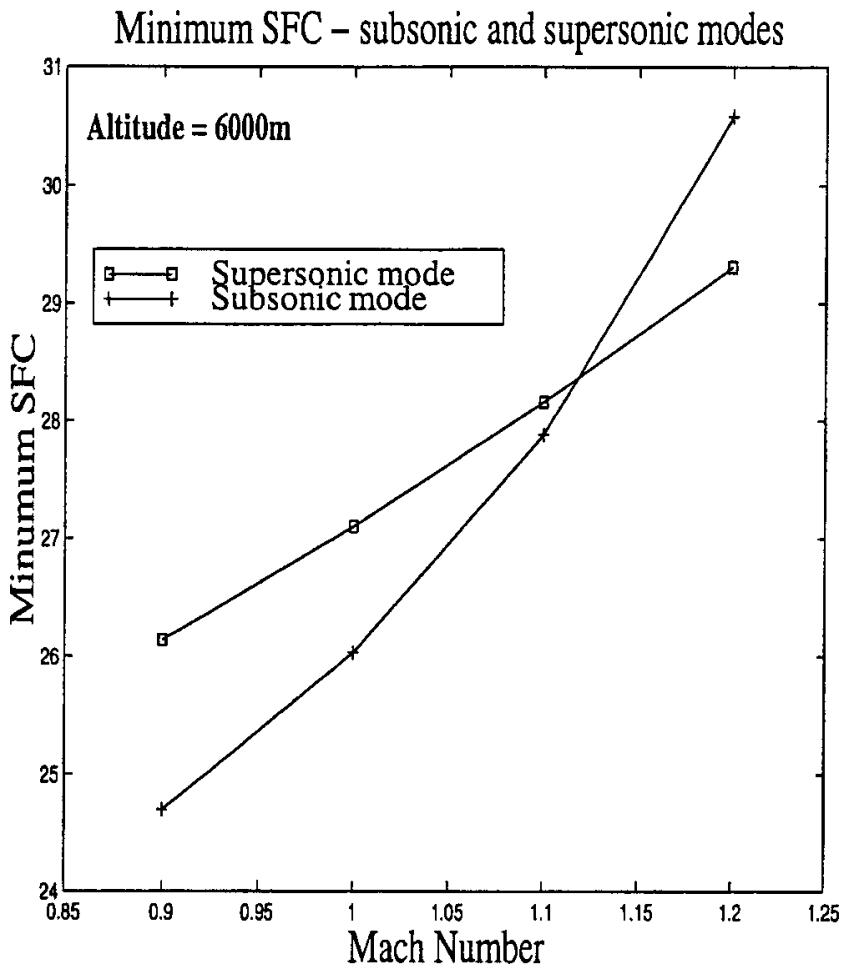

Fig. 2 Minimum specific fuel consumption (SFC) for the two modes

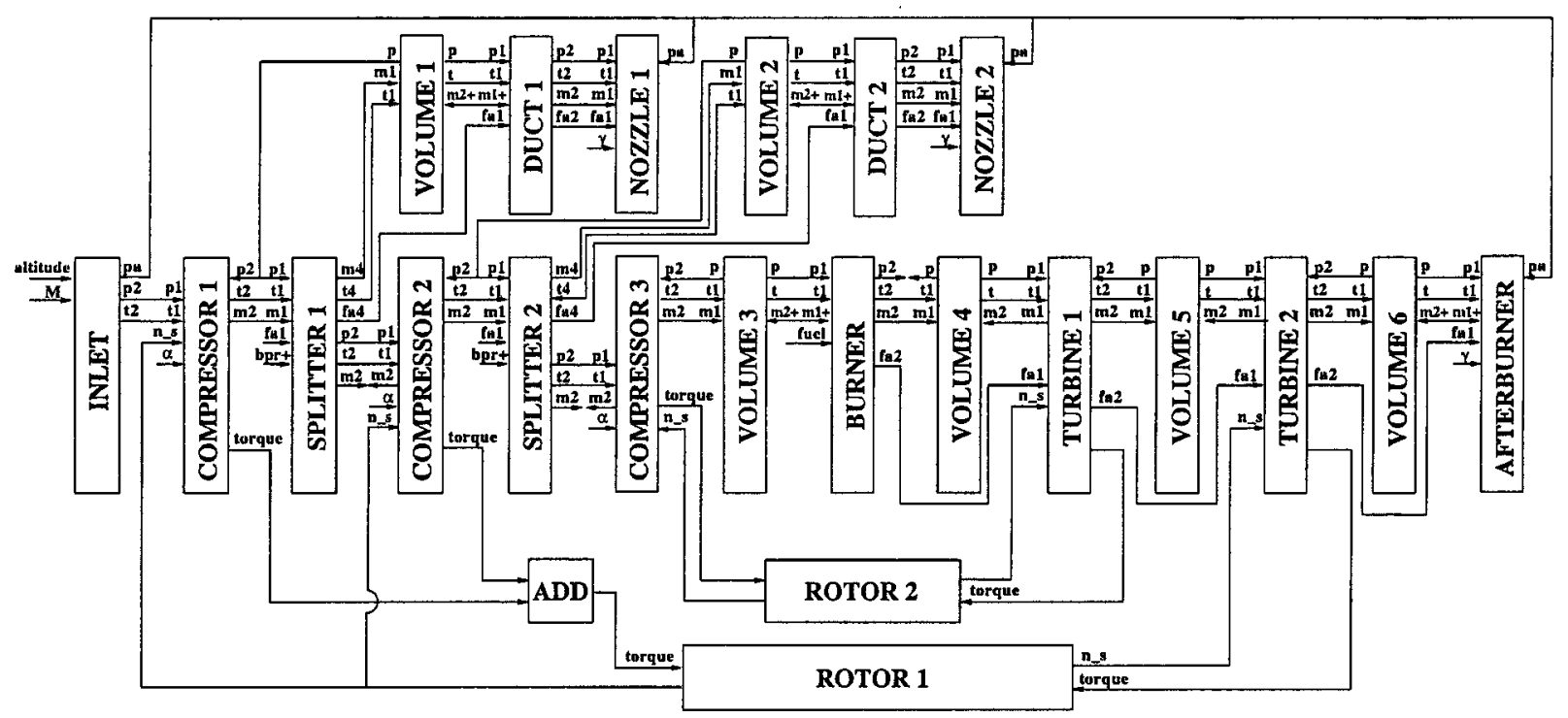

Fig. 3 Wiring diagram of the transient selective bleed variable cycle engine (VCE) model 


$$
\Psi=\frac{\pi-\pi_{\text {choke }}}{\pi_{\text {surge }}-\pi_{\text {choke }}} .
$$

By this definition surge would occur for $\Psi=1.0$. Thrust requirements for the entire flight mission of the STOVL aircraft have been given in Nascimento and Pilidis [1].

The selection of the transition point is of crucial importance for the successful control of the transient. For instance, if the rotational speeds of the subsonic mode cruise point and the supersonic mode cruise point differ considerably, inertia of the rotors will make it very difficult to perform the transient within a reasonable time. Also, if the steady-state cruise points are selected too close to the limits of safe and stable operation, the margin is likely to be insufficient for carrying out a successful mode transition. For this reason a more conservative selection of constraints was made for the steady-state cruise optimization.

The original design point optimization of the supersonic mode of the selective bleed variable cycle engine was carried out for a flight Mach number of 1.2 and an altitude of $6000 \mathrm{~m}$ ([1]). For comparative reasons this altitude was selected for the mode transition. A number of optimizations of the control settings were carried out to determine a suitable Mach number for transition. The optimal cruise SFC curves for the two modes are shown in Fig. 2. Although Fig. 2 indicates that the most optimal point for transition is around $M=1.12$, the $(h=6000 \mathrm{~m}, M=1.2)$ flight case was the final selection of transition point, since this flight case was the supersonic mode design optimization point and also part of the STOVL aircraft mission specification.

The fact that the thrust requirement of the engine can be achieved also in the subsonic mode, indicates that the engine has
Table 3 Cruise optimized control settings for the transition point $(M=1.2, h=6000 \mathrm{~m})$

\begin{tabular}{lcc}
\hline \hline & Subsonic Mode & Supersonic Mode \\
\hline LPC restagger & $-2.03696 \mathrm{deg}$ & $4.44104 \mathrm{deg}$ \\
IPC restagger & $12.2441 \mathrm{deg}$ & $-9.66672 \mathrm{deg}$ \\
HPC restagger & $-0.772156 \mathrm{deg}$ & $-0.531882 \mathrm{deg}$ \\
Front nozzle & $0.331422\left(\mathrm{~m}^{2}\right)$ & $0.000000\left(\mathrm{~m}^{2}\right)$ \\
Mid nozzle & $0.000000\left(\mathrm{~m}^{2}\right)$ & $0.116615\left(\mathrm{~m}^{2}\right)$ \\
Exhaust nozzle & $0.456220\left(\mathrm{~m}^{2}\right)$ & $0.741889\left(\mathrm{~m}^{2}\right)$ \\
Fuel flow & $4.105108(\mathrm{~kg} / \mathrm{s})$ & $3.927331(\mathrm{~kg}) \mathrm{s})$ \\
\hline \hline
\end{tabular}

been somewhat oversized. This observation is further strengthened by the fact that the highest turbine inlet temperature required for any of the STOVL aircraft mission thrust requirements was $1577 \mathrm{~K}$.

The optimization problem was solved using sequential quadratic programming. The NAG implementation of the algorithm, based on the work of Gill et al. [6] was found to work very efficiently.

The new dynamic connection feature of GESTPAN made it very simple to specify the subsonic and supersonic modes with the engine design specified in Table 1 as the starting point. The subsonic mode was obtained by deleting all connections to the DUCT 1 and NOZZLE 1 modules, see Fig. 3 (note that the steady-state model used for finding optimal cruise points has no rotor or volume components). The supersonic mode was obtained in the same way.

The variable geometry and fuel flow schedules for the two
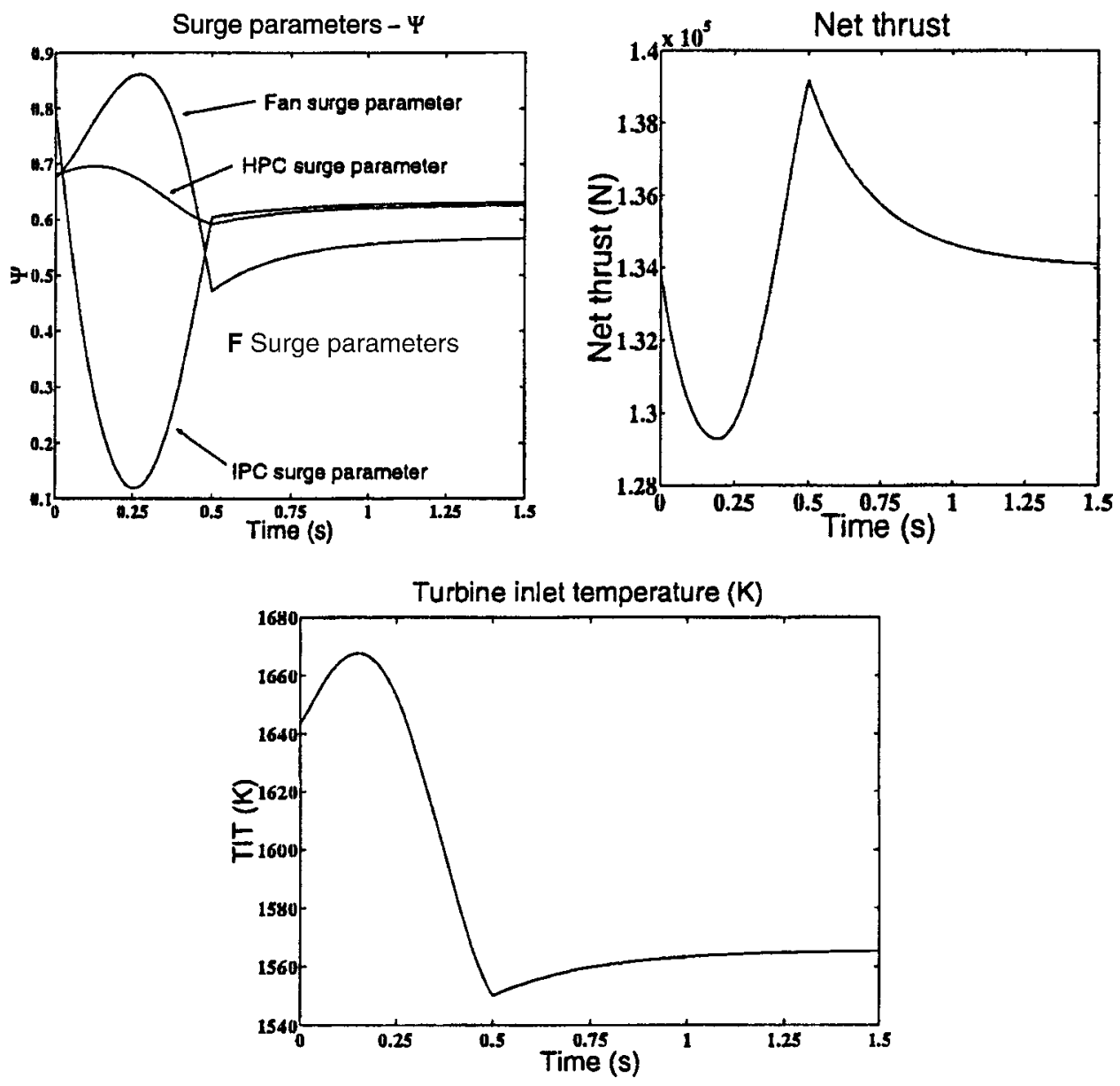

Fig. 4 Constraint variables-linear scheduling of controls 

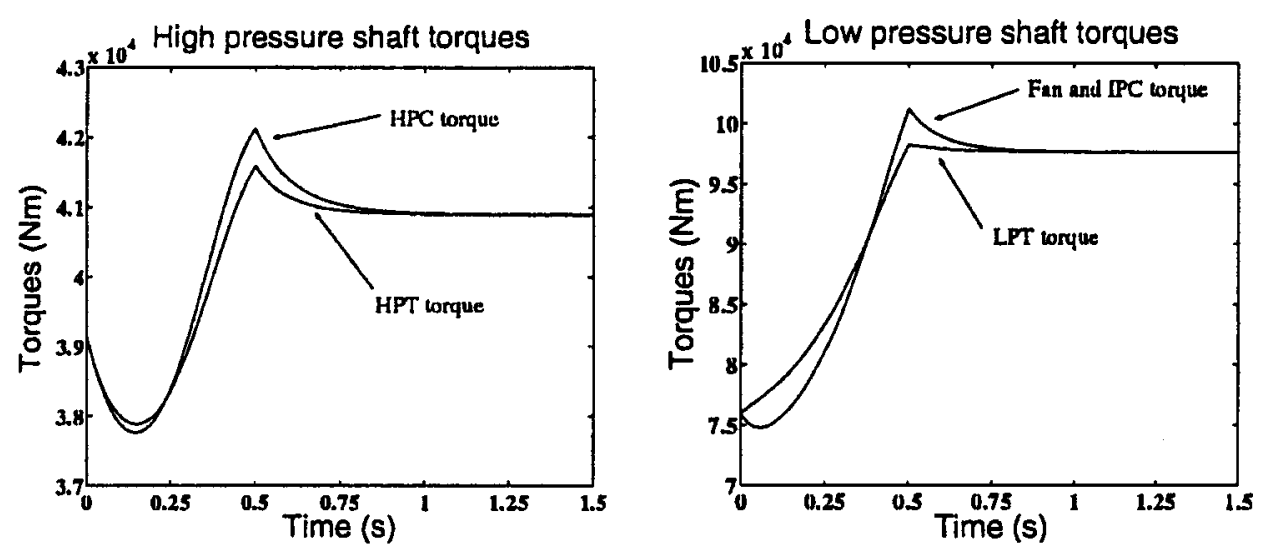

(a) $I_{L P}=15 \mathrm{kgm}^{2}, I_{H P}=10 \mathrm{kgm}^{2}$
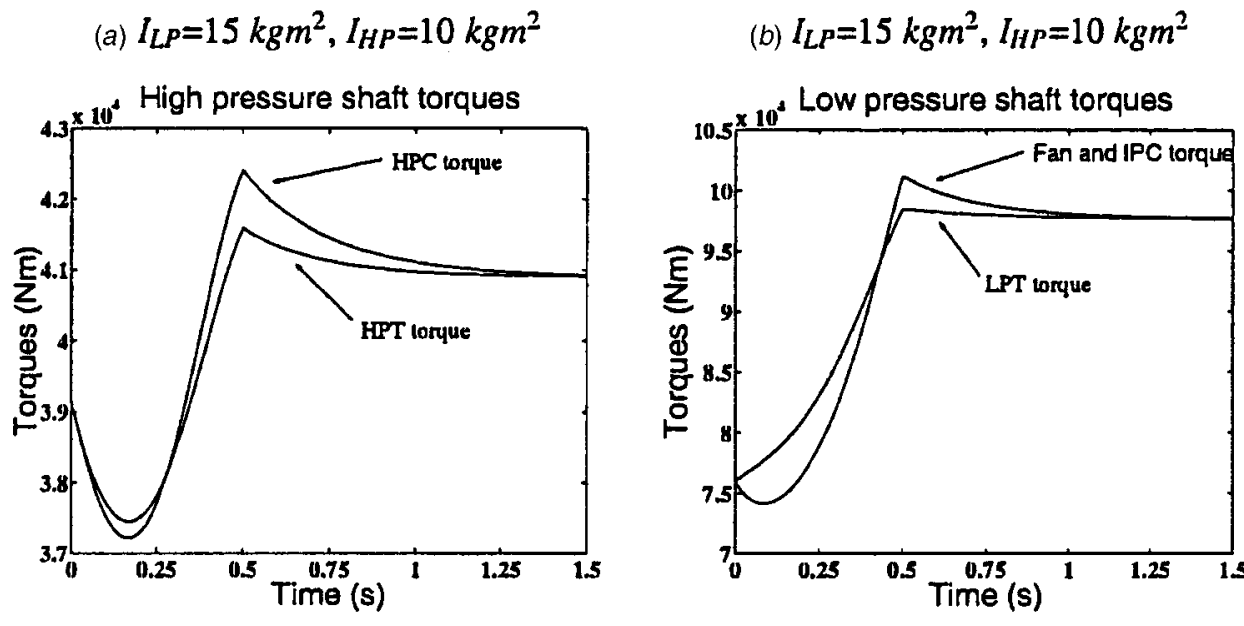

(d) $I_{L P}=30 \mathrm{kgm}^{2}, I_{H P}=20 \mathrm{kgm}^{2}$

(c) $I_{L P}=30 \mathrm{kgm}^{2}, I_{H P}=20 \mathrm{kgm}^{2}$

Fig. 5 Effect of doubling shaft inertias

modes were selected by optimizing the cruise SFC for this flight condition. The optimal control settings are given in Table 3 .

Another approach to model the two engine modes would have been to use the intermediate mode model directly, by using very small areas to model the closed nozzles. However, this would add additional numerical difficulties due to the small mass flow operating range of the nozzles. Attempts to use the intermediate mode directly for optimization were made, but they were not successful.

\section{Optimization of the Mode Transition}

To model the transition trajectory an inter-component volume model was assembled. The wiring diagram of the engine model is illustrated in Fig. 3.

Numerically the engine was represented by a differential algebraic equation system with 14 states and 6 equations. The numerical procedure used to solve the equations has been outlined in detail in the work by Grönstedt [7] which is based on the public domain code DASSL developed and implemented by Petzold [8]. The DASSL code is a variable order, variable step length, backward differentiation method (implicit method) used to solve the differential and the algebraic equations simultaneously. Further description of the use and the underlying theory of the DASSL solver can be found in Brenan et al. [9].

The start and end points of the trajectory were approximated as intermediate points with nozzle areas 0.0001 times the areas given in Table 3. The optimal control schedules obtained for the sub- sonic and supersonic mode cruise points were not corrected for this very small deviation in initial and end points.

Optimality Criteria During Mode Transition. To ensure safe operation of the engine during the mode transition all three compressors must operate well away from the surge line. Furthermore, the engine thrust should not drop below the aircraft thrust requirement. A small increase in thrust during the transient is probably in agreement with most aircraft system requirements. The surge margin requirement was relaxed for the transient mode switch and was limited to 0.95 . Also, the turbine inlet temperature was allowed to reach $1700 \mathrm{~K}$ during the transient. Shaft inertias were set to $I_{\mathrm{LP}}=30 \mathrm{kgm}^{2}$ and $I_{\mathrm{HP}}=20 \mathrm{kgm}^{2}$, and volume sizes were all set to $0.0001 \mathrm{~m}^{3}$. The selection of the rotor inertias and volume sizes are motivated below.

Linear Interpolation of the Schedules. The first attempt to control the engine during transition was made by a simple linear interpolation of the optimal schedules determined for the subsonic and supersonic mode cruise points. The engine was scheduled to switch within 0.5 seconds. The resulting surge margins, thrust and turbine inlet temperature trajectories are shown in Fig. 4. It is observed that there is a drop in thrust during the first fraction of the transient, but the compressors operate well away from surge.

Component Modeling Assumptions. The component offdesign behavior has been predicted using a number of empirical correlations described in Grönstedt [10]. These correlations do not 

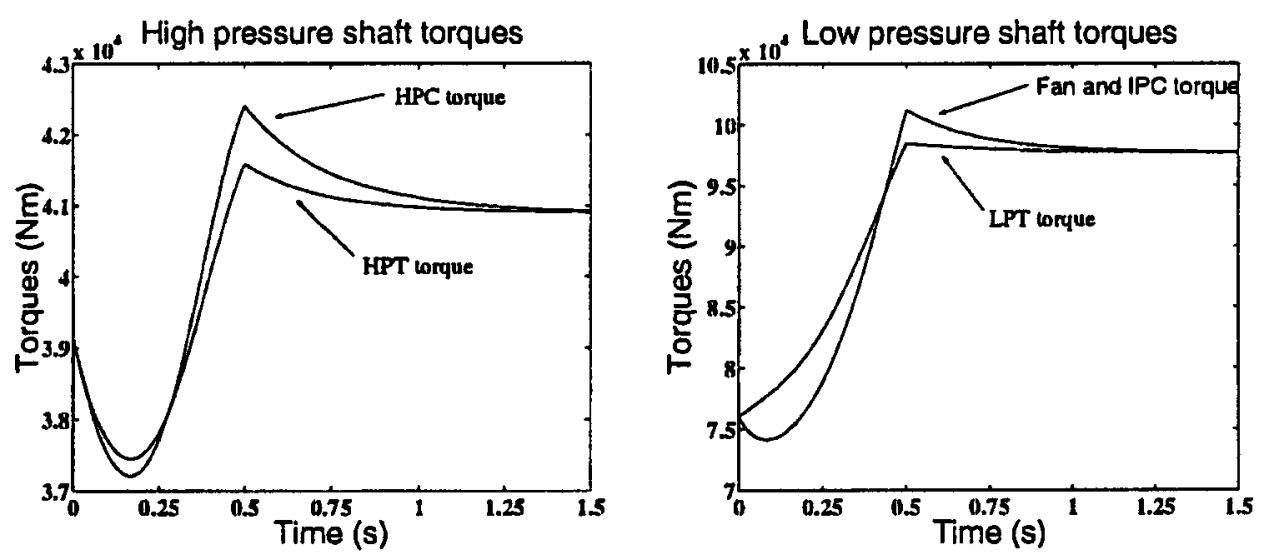

(a) $V_{i}=0.0001 \mathrm{~m}^{3}$

(b) $V_{i}=0.0001 \mathrm{~m}^{3}$
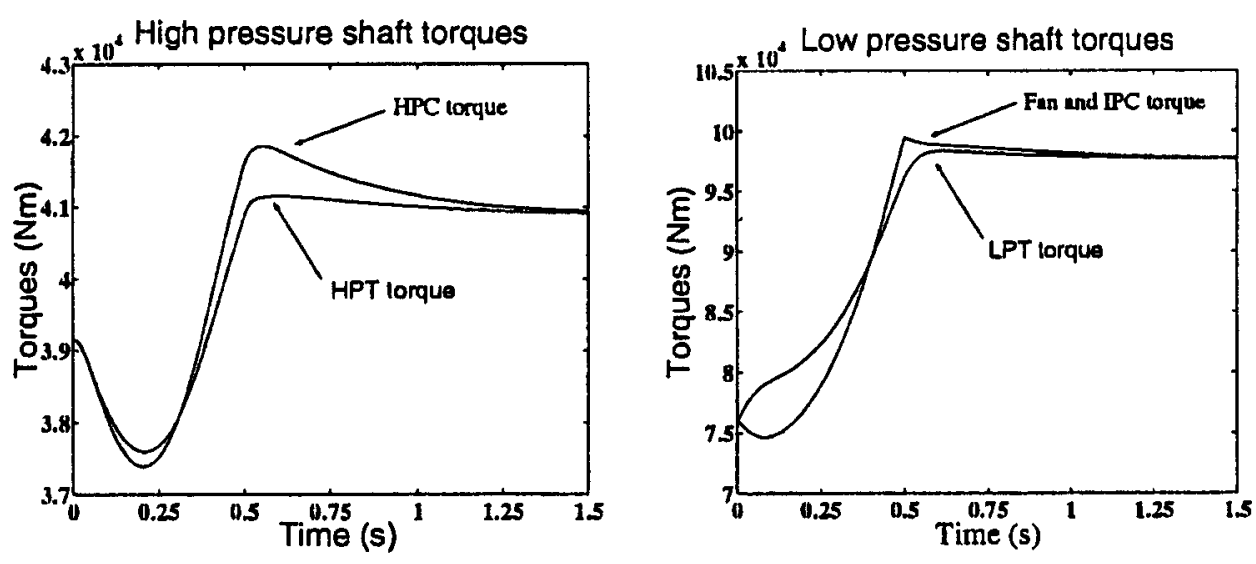

(c) $V_{i}=0.5 m^{3}$

(d) $V_{i}=0.5 m^{3}$

Fig. 6 Effect of change in intercomponent volume sizes

include any methods for estimating the moment of inertia of the shafts or the inter-component volume sizes. However, the dependency of the trajectory on the values selected for the shaft inertias and the volume sizes was observed to be very limited.

Dependency on Shaft Inertia. Since the high pressure shaft only changed its rotational speed from $153.7 \mathrm{rps}$ to $158.1 \mathrm{rps}$ and the low pressure shaft from $207.4 \mathrm{rps}$ to $205.0 \mathrm{rps}$ the effect of uncertainty in estimating shaft inertias on the trajectory was very limited. The shaft torques for two simulations with different values on shaft inertia are shown if Fig. 5. The proximity of the turbine and compressor torques also demonstrate that the intermediate points are relatively close to equilibrium points.

Dependency on Inter-Component Volume Sizes. Since the dynamics of the volumes is much faster than the time required for the mode switch the effect of uncertainties estimating volume sizes is also limited. Two simulations with volume sizes of 0.0001 $\mathrm{m}^{3}$ and $0.5 \mathrm{~m}^{3}$ are shown if Fig. 6. Note that the implicit solver technique makes the use of very small volume sizes possible, without any notable change in computational time. Very small volumes give rise to eigenvalues with large negative real parts, which makes the ordinary differential algebraic system stiff. The efficiency of the implicit solvers for solving stiff problems are related to their large stability regions which, in contrast to the explicit methods, causes the accuracy and not stability to be the limiting factor for increasing the time steps. Several authors have reported the successful use of low-order (first/second) implicit solvers $([11-14])$ and recently also high-order implicit solvers ([7]), for the efficient solution of stiff gas turbine transients.

Optimization of the Trajectory. Since the linear interpolation of the control schedules produced an initial drop and a fairly large variation in thrust, some further development of the control methodology was undertaken. The initial $0.5 \mathrm{~s}$ during which the control scheduling occurs was discretized into three time intervals; $(0,0.167), \quad(0.167 .0 .333)$ and $(0.333,0.5)$. At $t$ $=(0.167,0.333)$ the values of the nozzle area schedules, the burner fuel flow and the IPC variable geometry parameter were allowed to vary with 20 percent around the schedules produced by the linear interpolation. The control settings at all the intermediate points could then be obtained with interpolating cubic splines ([15]).

The resulting control optimization problem thus had eight degrees-of-freedom. The constraints on the compressor surge margins, the turbine inlet temperature and the thrust trajectories form five nonlinear constraints. The goal function was formed by minimizing the maximum thrust during the mode switch. This selection of goal function would minimize the total thrust variation.

Final Control Settings. The surge margins, turbine inlet temperature, and thrust trajectories resulting from the optimization are shown in Fig. 7, and the corresponding control parameters are shown in Fig. 8. Both the fan surge constraint and the turbine inlet 

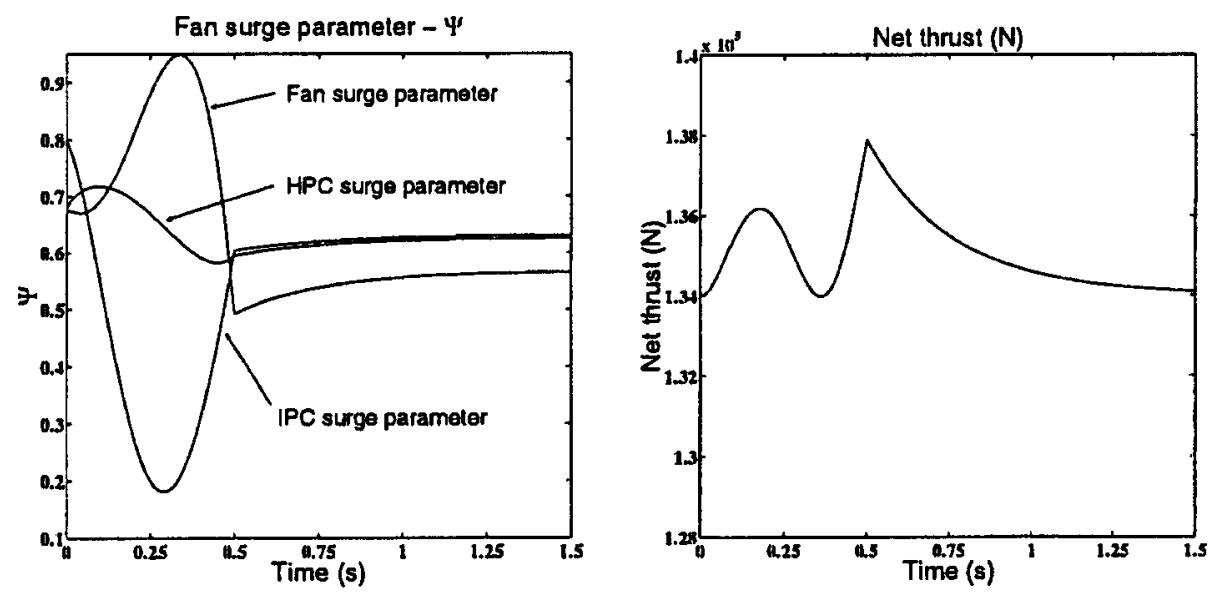

Turbine inlet temperature (K)

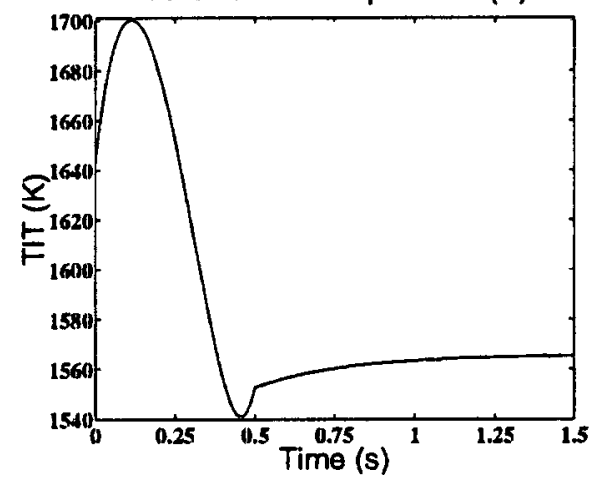

Fig. 7 Constraint variables-optimized scheduling of controls
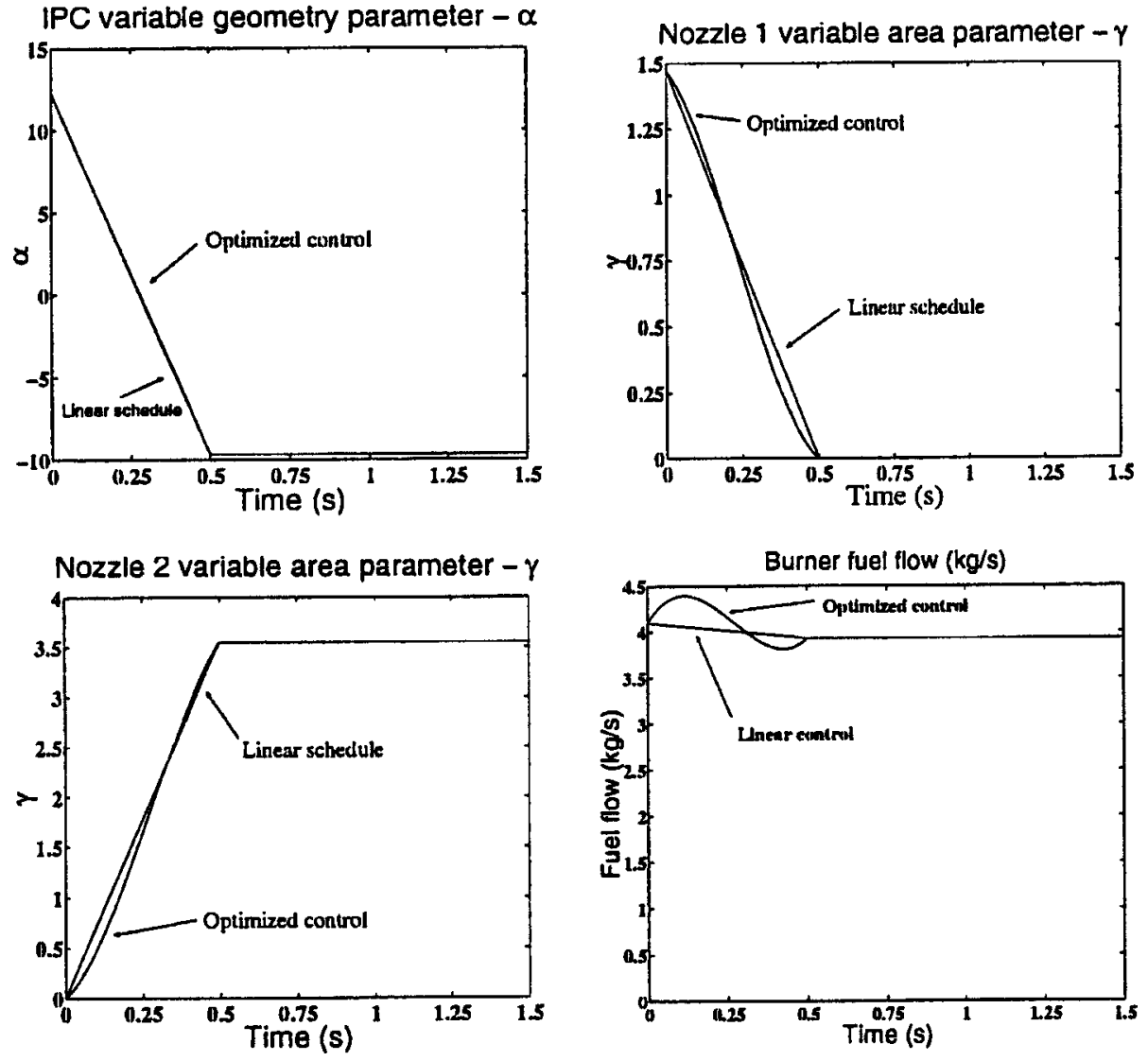

Fig. 8 Control schedules

80 / Vol. 124, JANUARY 2002

Transactions of the ASME 
constraint are active, i.e., the maximum allowed value is obtained at some point along the trajectory. The optimization has eliminated the initial drop in thrust and total variation in thrust has been reduced from 7.4 percent to 2.9 percent.

This methodology can be further refined by introducing more discretization points of the control variables as well as using also the fan, the HPC and the afterburner area variable geometry parameters as optimization variables. Too many discretization points might result in control schedules requiring variations in control signals to occur faster than the response times of the control system. Furthermore, such refined controls might be misleading if the accuracy of transient model is not sufficient. Also, large variations in the schedules can cause convergence problems for the differential algebraic solver, e.g., some combination of control variables evaluated during optimization could cause some of the nonlinear component models to operate outside their region of definition. However, the present results are sufficient for demonstrating the usefulness of the method and also to demonstrate that the transient can be controlled both safely and efficiently.

\section{Conclusions}

It has been shown that the mode switch of the selective bleed VCE can be carried out safely without violating surge and thrust constraints, and that the time for the mode switch is of the same order as the actuator times of a typical hydraulic system. Also, the modeling uncertainties introduced due to the estimation of the inter-component volume sizes and the shaft inertias were very limited on the trajectory selected for the mode switch. Furthermore, it has been observed that the thrust requirements set by the aircraft mission can be fulfilled at a considerably lower turbine inlet temperature than has been reported by previous authors. This indicates that by an optimal use of the control system the present design can be downsized.

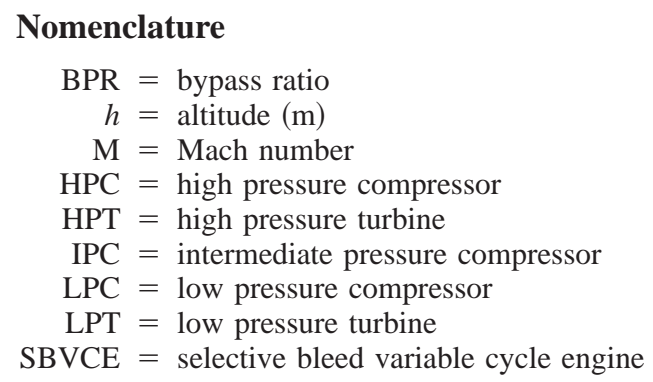

$\mathrm{SFC}=$ specific fuel consumption $(\mathrm{mg} / \mathrm{Ns})$

$\mathrm{SQP}=$ sequential quadratic programming

STOVL $=$ short take-off vertical landing

$\mathrm{TIT}=$ turbine inlet temperature $(\mathrm{K})$

$\mathrm{VCE}=$ variable cycle engine

$\Psi=$ surge margin

$\pi=$ pressure ratio

$\eta=$ isentropic efficiency

\section{References}

[1] Nascimento, M. A. R., and Pilidis, P., 1991, “The Selective Bleed Variable Cycle Engine," ASME Paper 91-GT-388.

[2] Nascimento, M. A. R., 1992, "The Selective Bleed Variable Cycle Engine," Ph.D. thesis, Cranfield Institute of Technology.

[3] Ulizar, I., and Pilidis, P., 1995, "Transition Control and Performance of the Selective Bleed Variable Cycle Turbofan," ASME Paper 95-GT-286.

[4] Oggero, L., and Pilidis, P., 1998, "A Novel Optimization Method for Variable Cycle Engines," ASME Paper 98-GT-142.

[5] Grönstedt, U. T. J., 2000, "Development of Methods for Analysis and Optimization of Complex Jet Engine Systems," Ph.D. thesis, Chalmers University of Technology.

[6] Gill, P. E., Murray, W., Saunders, M. A., Hammarling, S. J., and Wright, M. H., 1986, "Users guide for LSSOL," Department of Operations Research, Stanford University, Report, SOL 86-1.

[7] Grönstedt, U. T. J., 1999, “Advanced Solvers for General High Performance Transient Gas Turbine Simulation Tools," 14th International Symposium on Air Breathing Engines, Florence, Italy.

[8] Petzold, L. R., 1983, “A Description of DASSL: A Differential/Algebraic System Solver," Scientific Computing, R. S. Stepleman et al., eds. North-Holland, Amsterdam, pp. 65-68.

[9] Brenan, K. E., Campbell, S. L., and Petzold, L. R., 1989, Numerical Solution of Initial-Value Problems in Differential-Algebraic Equations, Elsevier, New York.

[10] Grönstedt, U. T. J., 1997, "Mission Dependent Optimization of Advanced Fighter Engines," 13th International Symposium on Air Breathing Engines, Chattanooga, TN.

[11] Daniele, C. J., Krosel, M. S., John, R. S., and Westerkamp, E. J., 1983, "Digital Computer Program for Generating Dynamic Turbofan Engine Models (DIGTEM), " NASA-TM-83446.

[12] Chappel, M. A., and McLaughlin, P. W., 1993, "Approach to Modeling Continuous Turbine Engine Operation from Startup to Shutdown," J. Propul. Power, 9, pp. 466-471.

[13] Schobeiri, M. T., Attia, M., and Lippke, C., 1994, “GE-TRAN: A Generic, Modularly Structured Computer Code for Simulation of Dynamic Behavior of Aero- and Power Generation Gas Turbine Engines," ASME J. Eng. Gas Turbines Power, 116, pp. 483-494.

[14] Garrard, D., Davis, M., Jr., Hale, A., Chalk, J., and Savelle, S., 1997, “Analysis of Gas Turbine Engine Operability With the Aerodynamic Turbine Engine Code," ISABE97-7034, Chattanooga, TN, pp. 223-232.

[15] Dierckx, P., 1993, Curve and Surface Fitting With Splines, Oxford University Press, New York. 